\title{
Travesías e imaginarios urbanos en exploraciones y aventuras en Honduras
}

Miguel Barahona ${ }^{1}$

\section{RESUMEN}

El texto propuesto en este trabajo retrata la percepción particular del viajero norteamericano William Vincent Wells, un gran observador y a la vez propulsor de una serie de reflexiones sobre la sociedad hondureña visitada; en este sentido el análisis del texto se hará en base al planteamiento en que el viaje abre la mente e induce al escritor a reflexionar en sus apuntes aspectos sobre la ciudad y la sociedad, asimismo permite una toma conciencia del momento histórico que arroja información sobre cómo se encontraba la nación hondureña en el siglo XIX. Al igual es posible atisbar también cuáles fueron los motivos primordiales del viaje sobresaliendo diferentes aspectos como: la historia autobiográfica, la curiosidad, la búsqueda del conocimiento, la codicia, el ansia de fama, la búsqueda de aventuras, la apertura de rutas comerciales y un interés político.

Palabras clave: historia, autobiografía, aventuras, interés político, rutas comerciales, Honduras.

\section{ABSTRACT}

The summary proposed in this work shows the particular perception of the American traveler William Vincent Wells, who was a great observer and also drive a series of reflections of the Honduran society visited. In this sense the text analysis will be based on the approach in which the travel opens the mind of the writer and leads him to reflect on his notes and the aspects of the city and society. Also it allows an awareness of the historical moment which gives information about the situation of the Honduras nation in the Nineteenth Century. As you may also glimpse what were the primary reasons of the trip; standing different aspects such as the autobiographical story, curiosity, the pursuit of knowledge, greed, lust for fame, adventure seeking, the opening of trade routes and political interest.

Key words: history, autobiography, adventure, political interest, trade routes.

\footnotetext{
${ }^{1}$ Universidad Nacional Autónoma de Honduras. Facultad de Humanidades. Escuela de letras, miguel.barahona@yahoo.es
} 


\section{INTRODUCCIÓN}

\section{Sobre los viajes: la contribución de una tipología cultural, social e identidad y de género}

Es preciso indicar que en este estudio de naturaleza ensayística el presupuesto fundamental se basa en que la literatura de viajes ${ }^{1}$ en relación al autor-viajero refleja una doble articulación: la íntima desde la óptica de la descripción y la relación que tiene la perspectiva universalista egocéntrica generada por el contacto cultural que tiene el autor-narrador al visitar nuevas regiones que le resultan exuberantes y desconocidas. Y es que el viaje desde el punto de vista literario es un entramado recurrente donde sitúa al autor-narrador en una constante de espacio y tiempo, en el cual se va articulando una fascinación por lo descubierto, además, de la descripción detallada de la sociedad visitada ${ }^{2}$. En primera instancia se definirá la literatura de viaje, ya que esta tiene doble función como lo indica Luis Alburquerque (2004: 504): "función poética y función representativa muestran la cara y la cruz de la moneda en este género. Cuanto más nos acercamos hacia la primera, más palpable se hace su condición literaria, y a la inversa, cuanto más nos aproximamos a la segunda, más se acentúa su carácter histórico y documental. En el filo de ambas funciones se desenvuelve este género que algunos han denominado, por esta razón, bifronte cuya naturaleza ambigua lo ha llevado en ocasiones a ser desterrado del palenque literario". Partiendo de la premisa de que la literatura viajera contiene una función histórica documental y una doble articulación óptica: la intimista y la egocéntrica como producto de la ideología del autor narrador ${ }^{3}$, vamos a realizar un análisis del

\footnotetext{
${ }^{1}$ En un artículo publicado en Istmo se hizo una apología sobre la literatura viajera donde se explicaba lo siguiente: "La literatura de viaje es un subgénero dentro de la narrativa que ha existido a lo largo de los siglos y que ha ido evolucionando. A través de este subgénero literario se puede conocer, desde variados puntos de vista, la geografía, la cultura y la historia de los países; así también la personalidad del autor en conjunto con los datos autobiográficos. El vínculo que existe entre el viaje y la aventura hace que esta literatura siempre haya sido recibida con beneplácito por el público lector en diferentes épocas. De esta forma las diferentes modas, sucesos históricos, descubrimientos de distintas culturas se daban a conocer desde el punto de vista del viajero". (Miguel Barahona: 2007).

${ }^{2}$ El viaje también es semejante a la creación de imágenes. Según Porter (1993:53) el viaje es crear paisajes sensuales y hermosos.

${ }^{3}$ En este apartado es bueno ver la otra cara de la moneda y considerar la propuesta de Edward Said que en su libro Cultura e Imperialismo parte de una convicción compartida, según la cual todas las culturas tienden a construir representaciones de las culturas extranjeras para aprehenderlas de la mejor manera posible o controlarlas de algún modo. Pero observa que no todas las culturas construyen representaciones de las culturas extranjeras y de hecho las aprehenden y controlan. Pero, por otra parte, en este libro Said introduce una nueva visión del otro, la visión ilustrada de los vencidos, entendiendo por tal la respuesta de intelectuales africanos, asiáticos, americanos y europeos a la dominación occidental, en lo esencial anglofrancesa, que ha culminado en el gran movimiento de descolonización del llamado Tercer Mundo .La propuesta de Said se dan en las relaciones de la Cultura e imperialismo puede, sin duda, provocar reticencias en una época, como la nuestra, que desconfía de las cosmovisiones. Y, obviamente, ha habido críticas en ese sentido. Said se anticipaba a esas reticencias declarando su convicción de que es imposible abarcar en un solo libro todo el imperialismo y toda la cultura que el imperialismo occidental ha producido en relación directa o indirecta con las colonias. Él mismo se ha considerado, temperamental y filosóficamente, contrario a las vastas sistematizaciones o teorías totalizantes de la historia de los hombres (Said: 2004:38).
} 
texto de William Vincent Wells (1982) Exploraciones y Aventuras en Honduras. Este libro narra el periplo del viajero norteamericano quien en el año de 1854 recorrió territorio hondureño dentro de una ruta que comienza desde el sur de la República en dirección hacia el este, precisamente hacia la región del departamento de Olancho. Después de esta breve introducción preliminar, se va a intentar conceptualizar una de las diferentes percepciones de los viajeros hacia una sola realidad enfocados en estos temas:

\section{Distintas percepciones de una realidad. La concepción de la sociedad visitada}

La visión que se tiene por parte del viajero de la sociedad visitada va a responder a la comprensión de un sinnúmero de fenómenos observados, nos referimos a esa cierta visión fundamentada generalmente en una serie de prejuicios que más sobre un conocimiento verdadero y sobre los que se perpetúan en cada uno de los escritos son repetidas en una multiplicidad de imágenes, que no sólo son muy limitadas sino que al mismo tiempo distorsionadas.

En el modelo de la literatura de viaje concebir la sociedad visitada equivale a reinterpretar, es decir, el producto de observar, reinterpretar una valorización crítica dialógica que no necesariamente debe coincidir entre la realidad y lo que se percibe y se describe, porque la noción humana de esa realidad va a pasar a través de un lente dicotómico que se basa en la relación asimétrica entre la distancia de ver e interpretar, este lente de cristal que tiene un filtro intermedio subjetivo, mismo que se relaciona directamente (por ejemplo) con la procedencia del viajero-autor, su ideología personal, el género y asimismo el espacio y tiempo del viaje y una aproximación a una reinterpretación de los hechos observados a su paso por las ciudades hondureñas. Pero interpretar ${ }^{4}$ es conjeturar y Wells responde a ella como el único método de validación al momento de describir la cultura hondureña aproximando su lógica descriptiva en ciertos puntos que muestran en el discurso escrito; de forma que cada argumentación va acompañada de una lógica personal cualitativa y cuantitativa.

Esta reinterpretación es subjetiva y va a crear el conflicto entre el texto mostrado y la valoración de la realidad. Y es que el texto en sí es una referencia propuesta a través de un racionamiento crítico personal. Sobre esta problemática de la interpretación

\footnotetext{
${ }^{4}$ Definido en el diccionario de la RAE (2007: 397) como: (Del lat. interpretāri). 1. tr. Explicar o declarar el sentido de algo, y principalmente el de un texto. 2. tr. Traducir de una lengua a otra, sobre todo cuando se hace oralmente. 3. tr. Explicar acciones, dichos o sucesos que pueden ser entendidos de diferentes modos. 4. tr. Concebir, ordenar o expresar de un modo personal la realidad.
} 
cultural Cliffort Geertz ${ }^{5}$ nos indica que para describir y analizar una cultura primero se deben desentrañar todas las estructuras de significación, es decir, conocer sus códigos el campo social y discernir y descifrar distinguiendo las diferentes estructuras y después conocer la razón y el porqué de la actuación de los individuos en esa cultura particular. En conclusión interpretar es tener una co-presencia en el lugar, conocer la historia de la sociedad y saber de todas las relaciones sociales. $Y$ es que la literatura de viajes no sólo es describir, sino también es traducir e interpretar la realidad visitada y esto transcurre sólo con observar, conversar con los individuos, establecer relaciones conocer la rutina, las costumbres, en sí tratar de leer cada parte del universo cultural.

Paul Ricoeur ( 2004:17) indica que "un mensaje es intencional, es pensado por alguien, es arbitrario y contingente" por lo cual dentro de los textos viajeros se desarrolla una descripción de la sociedad basada en el mensaje narrativo cuya intencionalidad del mismo depende de manera implícita a esa aproximación estructural desde la óptica particular de cada autor. Esa aprehensión de la cultura es solo una aproximación finita que parte de un criterio individual que postula una realidad, pero que difícilmente se acerca a la realidad concreta. La posición del autor viajero va a construir entidades culturales particulares fundamentadas en la comparación personal y en la combinación de hechos observados. Estas descripciones tienen un significado propio y cerrado, definido por la relación externa entre el visitante y los visitados. El hecho, por ejemplo, que el visitante sea un norteamericano va a erigir un discurso descriptivo particular. Así el autor construye el relato en base a criterios específicos, caracterizados por aspectos relevantes como el pensamiento ideológico de la sociedad donde procede, la formación académica y la experiencia viajera. Y es que la descripción de la sociedad hondureña aparece en el texto de Wells como la descripción de un mundo particular de diferentes elementos del sistema, con un sinnúmero de interacciones, de oposiciones, de diferencias constitutivas, es decir, la sociedad hondureña decimonónica es propuesta en los textos como unidimensional en una oposición al "yo" del viajero y las distintas entidades sociales con las cuales tienen contacto el autor.

\footnotetext{
${ }^{2}$ "La cultura es un documento activo, es pues pública. Aunque contiene ideas, la cultura no existe en la cabeza de alguien; aunque no es física, no es una entidad oculta. El interminable debate en el seno de al antropología sobre si la cultura es 'subjetiva' u 'objetiva' junto con el intercambio recíproco de insultos intelectuales ('idealista','mentalista','conductista', 'impresionista', 'positivista') que lo acompaña, está por entero mal planteada. Una vez que la conducta humana es vista como acción simbólica -acción que, lo mismo que la fonación en el habla, el color en la pintura, las líneas en la escritura o el sonido en la música significa algopierde sentido la cuestión de saber si la cultura es conducta estructurada, o una estructura de la mente, 0 hasta las dos cosas juntas mezcladas" (Geertz, 1982: 20-21).
} 
Esta descripción es una construcción sintética reductible considerada como la sociedad real. Con todas estas perspectivas de la concepción de la sociedad basada en la descripción y al mismo tiempo en la interpretación de la sociedad hondureña, mismas que son instauradas y dadas como válidas en el texto de nuestro estudio; mismas concepciones particulares y esnobista que encontramos en este fragmento presentado a continuación: "Los habitantes aparte de los miembros dignos y en extremo corteses de las viejas y ricas familias, muestran una extraña combinación de urbanidad, sencillez, sutileza y desfachatez y, sobre todo, una indescriptible indiferencia en sus rostros, que confunde al extranjero hasta que a éste, por fuerza de la costumbre, se le hace familiar, se paran a espiar dentro de las ventanas para escudriñar a uno en el acto de vestirse, $y$ al encontrarse con los ojos de uno, se vuelven y hacen una reverencia digna de un Chesterfield; ponen sus hogares y todo lo de ellos a nuestra disposición, pero están prestos a redondear al siguiente día cualquier negocio leonino a costillas de uno-, y así hasta el fin. Como todos los españoles o mestizos españoles, son grandes tahúres... Estos les viene de sus ancestros; $y$ en relación con los hábitos de pereza en un gran sector de la clase media..."(Wells: 175-176).

En el ejemplo anterior se aplica lo de la visión instruida de este viajero norteamericano que también transmite esa visión del mundo a través del "ojo instruido masculino que sostenía un sistema que podía familiarizar (naturalizar) los nuevos sitios / vistas inmediatamente y por contacto al incorporarlos al sistema del lenguaje" (Pratt: 1992:64). Estas narraciones expuestas conducen a una serie de análisis de los fenómenos sociales significativos que dan cuenta de esa visión sujetiva humana que persiste desde la óptica del autor al adentrarse a la sociedad hondureña. Y así, a partir del análisis de esa subjetividad en los fenómenos de significación como los símbolos sociales vertidos en los textos como por ejemplo en el caso de Wells: "el hondureño es haragán, es tahúr y esto heredado por los colonizadores españoles". Este discurso narrativo del viajero nos transmite y muestra una de las temáticas centrales de su pensamiento. Así, el lenguaje en que se describe (lenguaje a veces despectivo) será el medio privilegiado al acceso de dicha subjetividad de la sociedad descrita. Ya que desde el punto de vista personal del autor hace que su relativo conocimiento y la pobre comprensión de la sociedad

\footnotetext{
${ }^{6}$ Esa marca de holgazanería y pereza también es impuesta a las descripciones de los hondureños desde una mirada viajera a ciertos individuos dentro de la sociedad hondureña, misma que es señalada por el Alemán Jegór Von Sivers quien en el libro: A través de Madeira, las Antillas y Centro América Memorias de viaje e investigaciones publicado en 1861 dice: "Aquí en la costa es bastante numeroso el grupo de los criollos superando a estos el grupo de los llamados negros, quienes se destacan de los demás grupos respecto a la comprensión y al talento, pero lastima que son los más inútiles". (Yaxkin: XXV N 1: 131) Asimismo Mary Lester una viajera británica de a finales del XIX impone una marca al hondureño "Cómo todos los de su raza tienen la tendencia a ser haragán" (Lester 1964: 74)
} 
visitada no logra transmitir la realidad de forma directa y clara, sino que solo lo hace posible conocer a dicha sociedad a partir de mediaciones 0 de las expresiones significativas subjetivas (eso a lo que Pratt denomina "resemantización global" (1992:64); en este sentido se puede señalar que los sujetos sociales no se dan a conocer por sí mismos directamente, sino sólo a través de los signos depositados en la memoria del autor y el imaginario de la cultura visitada. Estos señalamientos erróneos hechos por los viajeros decimonónicos hacia la cultura centroamericana se pueden atribuir a una cuestión de óptica de la supremacía o los llamados estereotipos, que en palabras de Amy Gutmann (2008:9) se logran señalar y plantear por la disyuntiva del error de tomar grupos identitarios como la fuente de valorización social o como el único y exclusivo ejemplo de una sociedad ${ }^{7}$.

El mismo viajero no puede señalar una igualdad social o que en sí la sociedad visitada sea de índole homogéneo, aún en la cuestión de grupos identitarios los autores viajeros pueden fomentar estereotipos negativos ${ }^{8} \mathrm{e}$ incitar a los lectores a formarse una idea de esa cultura colectiva con ciertos marcadores, por ejemplo: de tahúres, haraganes, ociosos, vagabundos, lisonjero; al contrario debe reconocer más allá de esos aspectos sociales adversos, como el que ha continuación se muestra en un fragmento de Wells (que identifica la haraganería en razón de su procedencia geográfica):"es tan haragán como un olanchano" (Wells: $348^{9}$ ). Ahora es posible reconocer el hecho que la traducción cultural lleva a una singular pregunta ¿Cómo se hace posible a nuestra comprensión la cultura en sí? Y es que la idea de los viajeros en traducir la cultura se basa en un conocimiento mediado

\footnotetext{
${ }^{7}$ “...Cuando se identifica a las personas en términos de blanco o negro, varón o mujer, irlandés o árabe, católico o judío, sordo o mudo, se recurre a estereotipos de raza, género, ascendencia étnica, religión o discapacidad, y se les niega la individualidad que resulta de su propio carácter distintivo y de la libertad de adhesión según su voluntad Cuando los individuos mismos, a causa de haber sido identificados con cierto grupo, se reconocen por su raza, ascendencia étnica o religión, suelen generarse actitudes hostiles hacia otros grupos y un sentimiento de superioridad sobre los demás. Con frecuencia, los grupos rivalizan unos con otros sin concesiones, y sacrifican la justicia e incluso la paz con tal de reivindicar su superioridad como grupo".

${ }^{8} \mathrm{Y}$ hablando de estereotipos en referencia a lo haragán en los iberoamericanos llama la atención lo que dice Jean Plumyene al respecto de la pereza española en el libro: Catálogo de necedades que los europeos se aplican mutuamente:“Hay unanimidad en Europa Los españoles son perezosos... pues el pueblo español nunca se siente tentado por el trabajo, a menos que concurra una necesidad irresistible, ya que no descubre ventaja alguna de la industria...El misticismo y el instinto de gozar, que constituyen el fondo del carácter español, se ponen de acuerdo para fomentar la inactividad en España, tanto a base de contemplación como de despreocupación, o de ir pasando de una a otra (la alternancia, fenómeno profundamente español). Todo su ser , es decir, su instinto sostenido por su razón le dice que ahí está el bien soberano y que, por lo demás "la vida es sueño" (1973: 61-62).

${ }^{9}$ Pero las descripciones despectivas que hace Wells contrastan con lo que un hondureño dice al autorreferenciarse: "¿Me tomará? -Dijo el hombre - Soy medio indio, y el indio siempre tiene mejor oído y el paso más rápido. Se escribir también y leer- agregó- Un buen sacerdote tenía una escuela indígena. Algunos curas son muy malos aquí, pero éste, oh señora, era bueno con la raza india" (Lester: 107).
} 
desde el punto de vista personal. Siempre los enfoques del autor observador se basan en conceptos e indicios referenciales vistos desde su propia cultura, con lo que cada autor va a clasificar la realidad de los otros. Ya en su momento Gertz (1990: 23) nos plantea y explica sobre las interpretaciones en los escritos que describen una cultura: "este hecho que lo que nosotros llamamos datos son realmente interpretaciones de otras personas de lo que ellas piensan y sienten". Para confirmar lo de Gertz, he aquí un extracto del texto de Wells: "Fastidiado de tanto andar a caballo, desfallecido por el agotamiento y el hambre, usted se desmonta y después de saltar los charcos y zanjas, busca a tientas la entrada de la choza más grande entre una colección e ahumadas barracas de adobe, que más parecen moradas de hotentotes que de seres semicivilizados. Usted se contiene de no abrir la puerta, recordando a los perros, ante cuyos colmillos ni las botas, ni las sobrebotas son suficientes. Entonces usted grita en un argentino castellano, rogando ser admitido y la respuesta es un gruñido. Si usted agrega un aliciente pecuniario en un castellano más elocuente, la respuesta es una algaraza de chiquillos que chillan en coro y el regaño de la señora despertando a su compañero dormilón, a quien ordena abrir la puerta a los extraños..."(Wells: 227).

\section{Imaginarios e interpretaciones de la nación desde el aspecto económico y social}

En los textos se destacan los imaginarios que se acompañan como explicación sobre Honduras, mismos que se van desplegando en aproximaciones rudimentarias que se oponen y se comparan (hechos-valores, objetivo-subjetivo, inductivo-intuitivo) y que se van verificando de la misma forma en que se desarrolla el viaje. Dependiendo del prisma adoptado, el sujeto descrito, ya sea la sociedad o el individuo, tiene que ver con el relativismo cultural que tiene el autor viajero, es decir, con ese paradigma donde interviene una lógica empírica de formación cultural, es así que en este sentido se pueden observar dentro de las intervenciones del texto viajero que discurre como un papel argumentativo que da lugar al diálogo con los lectores y dentro de dicho discurso se abre un juego de posibilidades persuasivas traducidas en diferentes clasificaciones de conceptos sobre la nación visitada y que se pueden deshilvanar en los siguientes imaginarios:

1. Nivel económico: que muestra las condiciones que se encuentra la nación visitada. La primera concepción es desde una perspectiva cosmopolita que va ambientando la mirada viajera en función que considera que toda relación con los individuos y la sociedad debe tener una base económica y al mismo tiempo el autor ve a ese EstadoNación visitado como un ente que se puede percibir de una sola manera: la de los hombres que la conforman y la de los hombres que los gobiernan, todo visto desde una mirada espacial, es decir, desde arriba partiendo de una ideología económica: "Tegucigalpa, aunque no es el asiento del gobierno de Honduras, es la ciudad más 
grande y de más importancia en la república. Su población es hoy de 12,000 habitantes y se haya compuesta e una mitad entre "mestizos"y "mulatos" y otra mitad de blancos, negros cuarterones e indios. Los blancos puros están en pequeña minoría..." (Wells: 158-159 ${ }^{10}$.

2. Núcleo económico: cuando el viajero va observando esas relaciones de producción con esas fuentes eventuales a las cuales se les puede sacar provecho y obtener diversos beneficios tanto personales como de los patrocinadores del viaje. Asimismo observa las diferencias de los potenciales económicas que prevalecen en las regiones de Honduras, es decir que zonas son ricas y cuales no lo son. En cuanto al núcleo económico no se debe olvidar que por lo menos Wells es producto esencial de un país imperialista y dentro de esa lógica su visión individual siempre se va a observar a lo largo del escrito, esta visión que se funda y se contamina con la comparación de la economía y de una cultura dominante (de la cual proviene), por lo cual el discurso se va acompañar de palabras que van a observar, a medir, hacer cuentas y por supuesto a comparar en cuanto a la economía del país se percibe, además el viajero hace una constante búsqueda de información sobre la nación visitada: "Durante mis visitas a Tegucigalpa y sus alrededores, en las que gasté casi dos meses, hice de gran acopio de notas y extractos de las obras españolas y guatemaltecas relacionadas con la historia de las minas de plata y la condición política del pueblo.."(Wells:160").

\section{La observancia de las desigualdades sociales basadas en género. Cuyas} observaciones se van a presentar a lo largo y ancho de la sociedad hondureña.

\footnotetext{
${ }^{10}$ La narración siempre va presentando esa condición descriptora creando un mundo o esa realidad de él percibida de manera exótopica con lo cual cada autor generalmente va aportando con su mirada esas diferencias que le son perceptibles en el diario recorrido. Es así que en este texto de Wells es fácil apreciar cómo se puede configurar Honduras a partir de los habitantes y de su economía:"Honduras con sus 350,000 habitantes es un país que consume constantemente y produce muy poco..." (Wells: 199).

11

Aquí se muestran otros extractos textuales que hablan sobre este subtema"Los establecimientos comerciales de las ciudades más importantes de Honduras, están provistos todos de los mismos artículos; con unas pocas diferencias en cuanto a su tamaño y disposición, es describirlas a todos. Rodean el establecimiento sendos estantes y en el centro, detrás del mostrador, se halla el señor o a menudo la señora, tranquilamente sentados. 'Las mercaderías que se exhiben para la venta no son suntuosos ni caros, y consisten en su mayor parte de ropa para el uso de géneros de algodón, 'osnaburgs', mantas, calzados y los artículos corrientes...Casi todos combinan mercaderías de boticario, comerciantes de géneros, abarrotero, sombrerero, vendedor de calzado, talabartalero, librero, confitero y artículos de escritorio, pero con una provisión extremadamente limitada de cada una de éstas líneas..." (198). "Con estos datos, obtenidos por personas importantes y completados en la conversación que tuve con los nativos mejor informados que pude encontrar, hice los preparativos para dejar la ciudad..." (211)...."...Pero mis sencillos informantes muy pronto me dijeron que no sólo el Guayape era el único río que arrastra oro en Olancho..." (232)..."Cualquier tentativa de obtener una información fidedigna exacta en cuanto al monto de las exportaciones e importaciones en Honduras se estrella ante la falta absoluta de datos estadísticos, lo que deja al investigador en la obscuridad y hace muy dudoso el resultado de su labor. Las cuentas llevadas en las Aduanas de Trujillo y Omoa han desaparecido por negligencia, o se han perdido o destruido en las revoluciones tan corrientes en este país, de las cuales resultan cambios de funcionarios, a quienes importa mas su propio medro que la acuciosidad en el registro de las entradas del estado. En ausencia de fuentes de información fidedigna, tuvimos que apelar a la Aduana de los Estados Unidos en Boston, lugar por el cual la mayor parte, sino todo el comercio de Honduras con el Norte ha tenido lugar a través de dos firmas importantes y bien conocidas, que durante muchos años han tenido un comercio lucrativo..." (503).
} 
Entre los lineamientos usados por el autor sobresale la estrategia discursiva que se esboza en una continua descripción de referencias entre la distinción de los hombres y las mujeres ${ }^{12}$. Las descripciones de distinciones sociales siempre se basan en hechos de describir a los habitantes como un sistema de representación (es decir: cómo se visten, cómo caminan, qué hacen (entre otros) y los espacios sociales (frecuentados por cada núcleo social ${ }^{13}$ ). Pero la verdadera visión del género cómo categoría de análisis es propuesto por Kevin Rubén Avalos (1990: 73) en el artículo "Teoría feminista e historia de la mujer" quien en resumen dice que: "La categoría género es fundamental en el proceso de escribir la historia de la mujer. De hecho es clave en la teoría feminista para estudiar el fenómeno de subordinación de la mujer a la luz de la realidad social, y para demostrar la índole socio-cultural de la experiencia y el comportamiento femenino... es así que la introducción de género implica que la historia de la mujer no puede reducirse al sexo, sino que abarca todas las áreas de la sociedad ${ }^{14}$. En definitiva, la categoría de género permite redefinir a la mujer, y a que esta se redefina a si misma en su marco social...".

\section{Bajo esta premisa y contexto de la observancia de las desigualdades sociales ${ }^{15}$ comenzamos con las siguientes descripciones de género observadas y anotadas}

\footnotetext{
Leticia de Oyuela (1993: 122) dice que Wells: "vivió en Honduras una vida apacible y es interesante y necesario denotar cómo considera el viajero que la sociedad hondureña se mueve en función de las mujeres, quienes dinamizan ésta con su presencia y actividad..." Asimismo Oyuela hace una reflexión al final del capitulo del libro y dice: El viejo Wells , a su manera se enamoró de Honduras y, aunque el ambicioso contrato que soñó no fue lo productivo que él creyó, tuvo la intuición de descubrir la fuerza constructiva de la mujer hondureña". (Oyuela 1993:126).

13

Gannier (2001:8) les denomina « sistema de representación ». Él dice lo siguiente: « Le système de représentation du monde étant lié á une civilisation particulière, le mode de représentation du voyageur va être obligatoirement, puisque intermédiaire entre deux civilisations , un effort de conciliation, d'adaptions de léune au système de compréhension de l'autre. On peut alors s'appuyer sur la notion de « structure anthropologique de l'imaginaire... ».

${ }^{14}$ Al hacerlo, Wells proporciona otros espacios imaginarios. Se trata de la construcción de una realidad, de un sitio desde el cual la mujer puede trascender del aislamiento y de la domesticidad. Resulta evidente que el autor contrasta con la ideología de la época ya en su momento. Eva Figes (1970: 98) nos retrata la educación de la mujer en el siglo XIX de esta forma: "La insípida vida de la mujer de sociedad a pesar de la educación que se les daba a las muchachas, estaba limitada a las artes necesarias para conquistar un eventual marido, como podian ser la música, el baile...".

${ }^{15}$ Para fundamentar más este apartado del imaginario entre los hombres y mujeres que presenta y describe Wells podemos apoyarnos en el pensamiento que transmite el mismo viajero, quien da cuenta de una identificación más masculina basada en la vinculación que inscriben al componente comportamental y social de los hombres. De esta manera el concepto de género en el libro muestra distintas facetas del comportamiento femenino comparado con el masculino en plena y directa vinculación con lo social. Y es que William Wells, ellos no inventa en el escritos el concepto género, pero si lo convierte en un concepto central para la reinterpretación de las cuestiones de las desigualdades entre los hombres y las mujeres con diferentes comportamientos antagonistas estableciendo dicotomías como sexo versus género o en el mismo entorno de estos ya sea rural versus el urbano, en fin el género se convierte en una herramienta descriptiva para presentar y representar las desigualdades pertinentes y permanentes entre los hombres y las mujeres en ese siglo y así los el escritor construye una identidad de género.
} 
en primer término por Wells donde hace distinción de las mujeres de clase alta y clases bajas ${ }^{16}$.

4. Los fenómenos sociales. Referencias que recogen los autores fundamentalmente que dan cuenta de la forma de ese período marcado por los procesos de modernización económica, social y cultural, vistos en una perspectiva que exhibe el conocimiento de las amplias y complejas relaciones sociales que aparecen unidos a sujetos de la misma sociedad. Los autores de esta experiencia viajera dejan un testimonio escrito que pone en una lectura fecunda la relación entre viaje y la reafirmación de la constitución del imaginario en una zona social, donde sus puntos de contacto entre los diversos entes se dan en espacios públicos y espacios privados construyendo un novedoso objeto de lectura, en función de los fenómenos sociales acreditados a los hondureños, de la cual dichas figuras se van encadenando de un modo desde esa perspectiva y específicamente en los puntos de articulación y un cierto desplazamiento desde la crítica cultural. Así, el viaje en este punto será definido, más allá de las fronteras de un género y estará más vinculado a una saturada de una visión de significaciones sociales. Así las descripciones de William Wells están formadas de una variedad de elementos

\footnotetext{
${ }^{16}$ He aquí dos fragmentos donde Wells describe a las mujeres: Mujeres de clase alta: “...en las damas refinadas aquellas que fui presentado se hallaban muy a menudo ataviadas con tal refinamiento como se puede imaginar un extranjero. En toda la época del año los vestidos blancos o color rosa pálido, o de gaza diáfana celeste son los que predominan..." (Wells: 189-200)... "Muchas son graciosas e intrépidas amazonas...Usan sombrero... los guantes, adornados en el puño con hilos e plata y un pequeño fuete italiano completan el atavío" (201)..."Es muy raro ver a una dama fuera de casa, a no ser por las mañanas y a la caída de la tardecer, aún más raro aún verla acompañada de un caballero...Las manos y los brazos bonitos son demasiado comunes para ser tomados como marcas distintivas de la elegancia. Sin embargo, en varias ocasiones observé que las damitas se tomaban el trabajo especial para exhibir esas ventajas..." (200). Mujeres de clase baja:....todo el agua que se consume en Pespire es llevada en tinajas de barro sobre la cabeza de las mujeres. Escasamente habíamos salido del río cuando grupos de estas aguadoras, erectas y bien formadas, bajaron a las márgenes después de llenar sus vasijas imitaron nuestro ejemplo y se entregaron a la costumbre inmemorial de los trópicos, de darse un baño matinal. Algunas de ellas nadaban intrépidamente en medio del torrentes chapaleaban en las espumas como Náyades...luego recordé mi experiencia del baño y desde entonces respeto a los Centroamericanos por ser la raza con menos prejuicios de la tierra.(137) Descendimos por una empinada colina la Hacienda La Trinidad. Al ver mi amigo un grupo de muchachas bonitas en una activa preparación de queques...Desmontamos con muchos saludos y cumplidos de estas mujeres de ojos brillantes, siguiendo la costumbre del País, pero de repente se abrió una de las puertas del interior de la casa y apareció una vieja arrugada que nos saludó con un frío :Adiós señores (142) "Las mujeres del mercado permanecen alrededor en grupos, y pasan su tiempo platicando, en grupos, y pasan su tiempo platicando unas con otras, o a menudo riendo a carcajadas con los soldados o con los holgazanes que siempre se encuentran congregados bajo los aleros" (Wells: 164)..."El vestido de la mujer humilde de Honduras es de un material y ordinario tal como la guinga o la zaraza..." (199). "La cabellera se lleva preferentemente en moño trenzado..."En la calle se lleva siempre mantilla y no es sino reciente el uso de la sombrilla..." (200)... "Adelante iban dos mujeres llevando sendas canastas con un hueco en la parte superior..." (221). "Las indias, de plácida apariencia, empeñadas en sus quehaceres, nos observaban..." (242).
} 
sociales descriptivos diferenciados en espacio y tiempo. Conforme el escritor norteamericano pernocta en las grandes ciudades, comienza a verter información acerca de sus observaciones. Así Wells nos revela la ciudad vinculada a un sinnúmero de descripciones y detalles que le sirven en todo momento como puntos de convergencia en cada uno de los espacios urbanos visitados, es decir: las calles, el mercado, las casas, la gente.

Otro aspecto en la evolución del relato de Wells, es que describe el viaje ateniéndose a la sinopsis de la observación y luego nos lleva hacia un relato pintoresco, donde lo que cuenta es el sentimiento de sus observaciones y de todos esos datos descriptivos, el autor después pasa a los datos autobiográficos que en muchos casos es lo que más le interesa presentar y esto lo pone de manifiesto ante sus lectores. Por su lado Wells va a observar el país con una especial curiosidad anglosajona donde describe esos retazos de espacios sociales con sus figuras de la gente. Aquí unos ejemplos: Mientras caminábamos por una pequeña colina llamo mi atención hacia un claro en los árboles a través del cual obtuve mi primer vistazo de Tegucigalpa, situada en la extremidad Noroeste del extenso llano... El sol acababa de salir tras un banco de nubes cargadas y las torres blancas y los campanarios de la ciudad brillaban en la tarde a la luz del sol. Un magnifico arco iris tendía su comba en el valle y el verdor de las montañas adyacente, mezclado con los tintes purpúreos del declinante día, aumentaba el encanto del paisaje inseparable de estas recónditas reliquias de los mejores tiempos de España. Continuamos nuestro viaje por una sabana adornada de flores y moteadas de cactus .A intervalos echábamos una un vistazo a la ciudad por entre el follaje..." (Wells: 152).

Sucede que el viajero desea a veces transmitir esbozos de ese paisaje encontrado en ese mundo que transita, de lo que ha visto en esta ciudad: donde se combinan la arquitectura, las calles, la gente, con los espacios de luz y sombra, en armonía con la naturaleza. En el disfrute en la quietud del viaje tiene la sensación de que sus impresiones sólo se pueden expresar pintando un cuadro. Las opiniones y los juicios que entrega el autor, son más favorables y admirativos hacia el paisaje, los edificios y la arquitectura que observa a su paso por la ciudad: "Entramos por una calle pavimentada bordeada de casas bonitas de piedra y adobe revocado y las paredes pintadas de azul, rojo crema o blanco, según el gusto de sus propietarios. Los balcones con rejas; estrechas y herbosas aceras, los techos entejados, los patios empedrados, el estilo particular de la arquitectura me hicieron recordar más a La Habana que ninguna otra ciudad que yo hubiese visto en Centro América" (Wells: 153). 
El viajero se asombra de la variedad de situaciones que vive, las realza en una gama descriptiva de todo lo que va observando a su paso, así que da unas pinceladas narrativas, con su mirada de forastero, para hacer destacar el panorama que ofrece la ciudad: "El panorama que se contempla desde el puente que cruza el Río Grande, es interesante para un extranjero. Desde allí se puede ver un poco de la vista de Tegucigalpa. La mayor parte de las frutas y provisiones de las montañas y provisiones de las montañas circundantes y de los llanos bajos más allá de Comayagüela, es traída a la ciudad por este puente. El puente tiene diez arcos y sobre él hay una calzada de cuatro varas de ancho y cien de largo, toda la estructura es sólida y decididamente hispana... Todas las calles de Tegucigalpa tiene nombre, y la ciudad me impresionó a primera vista como una excepción a las consabidas ciudades centroamericanas, arruinadas y de apariencia desierta... (Wells: 153175).

Respecto a las personas, la narración va cambiando y se destacan aquellas que más le sorprenden:"Muchas personas se aventuran ahora a salir de sus casas y vagar sin rumbo por las calles con el paso típico que no se ven sino en las regiones españolas e italianas o en las de sus descendientes, deteniéndose a conversar un momento con un conocido dispuesto como ellos a comentar el chisme del día o a cambiar noticias sobre la revolución, o son algún viejo decrépito, a través de los barrotes de la ventana de la calle. Grupo de chicos panzones, algunos con solo la camisa y otros en estado de completa desnudez, de piel brillante como lustrosa caoba, saltan en la calle, mientras un grupo de espigadas y bien formadas mujeres encienden sus cigarros y, pausadamente, murmuran con la señora de la posada. De pronto la hora de la oración suena en la torre de La Parroquia. Al instante se acalla toda voz; los niños cesan en sus juegos como por instinto; un súbito silencio se impone y el movimiento de los labios con el murmullo rápido y mecánico de las formas acostumbradas para orar, se oye entre el grupo de las personas descubiertas. Una corta pausa y las campanas resuenan de nuevo en un alegre repicar; las conversaciones y juego se reanudan donde habían cesado, la noche avanza; una tras otra las puertas y ventanas se cierran y se atrancan; las calles se tornan desiertas..." (Wells: 57).

El autor va a presentar un tipo de ensayística antropológica, es decir, va a transmitir una identidad particular del hondureño. Pero no responde en el texto únicamente a la lógica del mismo autor básicamente porque no vemos desarrollarse una completa descripción siendo ello substituido por un difuso, aunque no por ello menos auténtico el intento de acceder a interpretar todo el ser de la cultura nacional hondureña. Es por medio de atisbos donde la reflexión se une a las obsesiones de hacer un retrato fidedigno: "Todo el mundo es cortés, no sólo entre las más altas 
sino entre las más bajas clases sociales. El más sucio vagabundo si zapatos, emplea un lenguaje comedido cuando se dirige a uno y parece imbuido de un sentido innato de fineza. Los hombres más amanerados que yo he encontrado en el mundo los vi entre las personas más educadas de Honduras. Sus caracteres más sobresalientes son una buena crianza, la urbanidad, y el deseo de ser agradables en reuniones. Las reyertas y disputas en la sociedad son casi desconocidas, y si una nueva persona llega a una reunión, todo el mundo se pone de pie y lo saluda" (Wells: 188-189).

\section{CONSIDERACIONES FINALES}

En este libro de literatura viajera se observa que el escritor actúa como un crítico postcolonial o un intelectual "de frontera" que parece navegar en un espacio del "otro"visitado, posicionado al país visitado entre el más marginal en comparación con el país de procedencia del viajero. En los espacios de los discurso de identidades propiamente encontrados en el texto produce algunos limitados efectos de demostración misma que no es posible apreciar la verificación dentro de una perspectiva de integración total, es decir que William Wells hace muchas veces distintas reflexiones de crítica pero con una visión escasa y de carácter personal en relación con sus ojos extranjeros que hacen de cada una de las palabras una seductora complacencia de contar un único punto de vista (el personal) y que generalmente se alejan de la realidad. Esto se aprecia al hacer una lectura del libro y al igual al comprender la relación que existe entre los discursos viajeros y la realidad social de la época muy específicos en las referencias que hace acopio el autor en cuanto a género, etnicismo y sociedad.

En fin este trabajo propuso presentar una evaluación axiológica de las condiciones discursivas de los estudios literarios en el libro de viajes para lo cual fue necesario considerar primero algunos rasgos específicos del lugar de enunciación de esos discursos críticos de Wells aceptando como punto de partida el momento histórico muy peculiar que se vivía en Honduras durante el año del viaje, asimismo abordar y aceptar la división de la escritura imaginada en la cual el autor plasma, describe e interpreta la cultura visitada con la premisa de cierto contexto que está marcado por diversas necesidades y deseos implícitos (de género, de clase, de etnia, de "cultura") que le parecen muy específicos; por lo tanto no intentamos criticar el postulado de las barbaries implícitas en el documento, sobre todo por esa visión imperialista mostrada por Wells, al igual por sus otros sistemas de dominación discursiva; donde el autor intenta desnudar (para el lector) los mecanismos institucionales e individuales de la sociedad de Honduras de a mediados del siglo XIX. 
En si, es posible apreciar que el viajero permanece dentro de esos imaginarios escriturales manteniendo múltiples esfuerzos por deconstruir la "barbarie", el multiculturalismo (que para él de alguna forma daña a la sociedad hondureña) además busca revelar las formas de poder percibidos (el establishment recalcitrante, dominante, monopolizante y económicamente poderoso ) en todos los estratos sociales superiores contactados y aportan un conocimiento de los "ilegítimos" que existen en lo marginal especialmente en cuestión de géneros. En si ese este ímpetu anti-multiculturalista se derrama en la reconfiguración del canon social que dan paso a ese algo o hiperbólicamente se puede llamar subalternidad.

Exploraciones y aventuras en Honduras puede ser considerado como un producto de las manipulaciones escritúrales de las literaturas viajeras clásicas y predominantes con orientación de dominio imperialista, donde la visión y la inclusión de las diferencias entre la sociedad de donde procede el autor y la sociedad visitada es una concesión oportunista que muestra y que disfraza un apetito global imperialista norteamericano on el recurso al exotismo ya definido como viaje del centro a la diferencia por Edmond de Goncourt (citado por Auerbach 1950: 468): "¿Por qué escoger ambientes? Porque en lo bajo se conserva el carácter de las cosas, de la gente, del idioma, de todo... [...] Quizás porque soy un escritor nacido en buena cuna, y el pueblo, el populacho si se quiere, tiene para mí el atractivo de las poblaciones desconocidas y aún no descubiertas, lo exótico que van a buscar los viajeros..."

En conclusión este texto viajero marca a ese "otro" quien termina siendo invocado como exótico, como sujeto "de afuera" más que como sujeto nacido por dentro mismo de la experiencia de lectura. Un otro, en suma, comprendido como "ausente", un convidado al que se le ha sustraído del contexto histórico, social y cultural; siendo éste el único patrón de referencia válido para el autor viajero, quien va evaluando las convergencias, los paralelismos 0 en todo caso las simultaneidades que explican sus rasgos distintivos de origen y muchas de sus propuestas como esa especie de revitalizado deconstruccionismo profundamente relacionado con la pseudo visión cultural que da paso a la muestra de un impulso descentrador y con sólido rechazo en primera instancia y permanente a todos los conceptos, a los presupuestos, a los valores sociales y culturales que rigen a la Honduras de esa época decimonónica; en si el libro mantiene una marcada calidad literaria elitista, reemplazante de las la ideas y de la realidad de la significación social o política de los hondureños de esa misma época. 


\section{AGRADECIMIENTOS}

Esta ponencia fue leída en el marco del $\|$ Congreso Internacional de Literatura y XXXII Jornadas Hispánicas y de América Latina: Ciudad e imaginarios en las literaturas latinoamericanas celebrado en la Pontificia Universidad Católica de Chile en Valparaíso en noviembre 2009. Viaje auspiciado por la Dirección de Investigación Científica de la UNAH. Este tema y trabajo de investigación personal fue concebido en el Diplomado Superior "Identidades, Ciudadanía y Globalización en Centroamérica", auspiciado por la Universidad Centroamericana (UCA) y la Fundación Ford.

\section{BIBLIOGRAFÍA}

Acuña Ortega, Víctor Hugo: (febrero 2009) Etnicidad y Nación: los debates actuales en las ciencias sociales, Diplomado Superior "Identidades, Ciudadanía y Globalización en Centroamérica", Managua, Nicaragua. Texto electrónico.

Alburquerque, Luis (2005). "Consideraciones acerca del género relato de viajes" en la literatura del siglo de oro", en Actas del congreso «El siglo oro en el nuevo milenio» tomo I, Carlos Mata y Miguel Sagasti (des), Pamplona, Eunsa, Pp. 130.

Alburquerque, Luis (2006) «Los libros de viaje como género literario», en, Estudios de la literatura de viajes, Madrid, CSIC (en prensa), 2006, Pp. 79.

Avalos, Kevin Rubén. «Teoría feminista e historia de la mujer» en Paraninfo año $5 \mathrm{~N}$ 9 julio 1990.Pp 73.

Barahona, Marvin. (1995) «Honduras el estado fragmentado» en Identidades nacionales y Estado moderno en Centroamérica, Arturo Taracena A, Jean Piel (Coords). Costa Rica: Editorial Universidad de Costa Rica. P, 97.

Barahona, Miguel. (2006) La búsqueda y construcción de la identidad: Los viajes de Hernán cortés y William V Wells a Honduras. Madrid: Tesis CSIC.

Barahona, Miguel. (2007) "A propósito del viaje. Analogía y subjetividad en Exploraciones yAventuras en Honduras de William Vincent Wells » Istmo 14.

D’Ans, André Marcel. (1997) Honduras. Difícil emergencia de una nación, de un estado. Honduras: Renal producción.

Figes, Eva, (1970) Actitudes patriarcales. Las mujeres en la sociedad. Madrid: Alianza Editorial.

Gannier Odile. (2001) Litteérature de voyage, Paris : Ellipsis.

García Buchard, Ethel. (2008) Política y Estado en la sociedad hondureña del siglo XIX. Honduras. IHAH.

Geertz, Clidfford, (1990) La interpretación de las culturas. Barcelona: Gedisa. Herranz, Atanasio. (1993) Estado, sociedad y lenguaje. La política lingüística en Honduras. Tegucigalpa: Guaymuras. 
Lesyter, Mary. (1982) Un viaje por Honduras. Costa Rica: Educa.

Marr Wilhenm.( 2004) Viaje a Centroamérica. Costa Rica: Editorial Universidad de Costa Rica.

Oquelí, Ramón. (1988) Bibliografía sociopolítica de Honduras. Honduras: Editorial UNAH.

Oyuela, Leticia de. (1993) Mujer, familia y sociedad. Honduras: Guaymuras.

Oyuela, Leticia de. (2001) Historia mínima de Tegucigalpa. Honduras: Guaymuras.

Pérez Brignoli, Héctor, (1990) Breve Historia de Centroamérica, Madrid: Alianza Editorial

Porter, D. (1993) Modernism and the Dream of Travel en Literature and Travel, Amsterdam: Rodopi.

Pratt, Mary Louise. (19992) Imperial Eyes, New York: Routledge.

Pratt, Mary Louise (1992) Ojos imperiales. Literatura de viajes y transculturización. Buenos Aires: Editorial Universidad de Quilmes.

Pratt, Mary Louise, (1990) «Woman, literature, and National Brotherhood» en Women, Culture, and Politics in Latin America, Berkeley and Los Angeles, University of California press, Pp. 49-52.

Plumyene, Jean. (1973) Catalogo de necedades que los europeos se aplican mutuamente. Barcelona: Barral.

Ricoeur, Paul. (2001) Teoría de la interpretación, discurso y excedente de sentido. México: Siglo XXI.

Rosa Izaguirre, Ramón (Ed) (2009). A lomo de mula. Viajando por Honduras y alrededores. Honduras: Multigráficos.

Sarmiento A. José. (2004) Historia de Olancho 1524-1877. Honduras: Editorial Guaymuras.

Said, Edward W (2004). Cultura e Imperialismo. Barcelona: Editorial Anagrama.

Schramm, Christina (2007) « Colocando América en el mundo" mirada, miradas y narraciones .El ejemplo de Wilhelm Marr »: Istmo 14.

Sivers, Jegór von (2009). «A través de Madeira, las Antillas y Centro América Memorias de viaje e investigaciones » (introducción de Miguel Barahona) en: Yaxkin XXV, N1, 131-162. IHAH Tegucigalpa

Tábora, Rocío. «La perspectiva de género». Límites y perspectivas. En Paraninfo, año 4 N5.Ppp125.

Wells, William. (1982) Exploraciones y aventuras en Honduras, Costa Rica: Educa.

Yurrita Maury, Pedro. (1967) Nomenclatura Etnográfica popular durante la colonia en Revista de la Academia Guatemalteca de Estudios Genealógicos, Heráldicos e Históricos. Guatemala N 1, pp 109-110

Zea, Leopoldo. (Coord) (1986) América Latina en sus ideas. México: Siglo XXI. 